\title{
An Autonomous Taxi Service for Sustainable Urban Transportation
}

\author{
Doros Nicolaides, Member, IEEE, David Cebon, and John Miles
}

\begin{abstract}
An autonomous taxi service has been proposed as a sustainable urban transport system for current and future cities. A critical review was conducted to examine whether the proposed technology can alleviate the negative side effects of urban transportation. The study investigated issues related to environmental impact, social sustainability and required infrastructure. A methodology was proposed to estimate the levels of demand and define the system performance requirements for an autonomous taxi to serve Addenbrooke's, which is a medical and research campus at the University of Cambridge UK. The size of the fleet, the capacity of the on-board battery and a charging infrastructure were suggested. Implications for the electricity supply network were also explored. A financial analysis showed that such a system is financial viable.
\end{abstract}

Index Terms - autonomous pods, economics, electric vehicles, infrastructure, power demand, urban transportation

\section{INTRODUCTION}

$\mathrm{P}$ ersonal mobility is a basic human need. The desire to move about and interact has been part of the human story since the beginning of the human life. For the last a hundred years, automobiles have been the predominant mode of transportation. They have enhanced dramatically our personal mobility and driven growth and prosperity. The free transportation of people and things between places has enabled greater access to jobs, goods and services in a convenient, safe and flexible way.

However, use of road vehicles has created negative side effects. The largest of these are congestion, accidents, environmental impact and noise. The average travelling speed in big cities can be under 10 miles per hour [1] and 1.2 million lives are lost each year due to road accidents [2]. Moreover, more than 20 million barrels of oil are consumed each day just for driving cars. This corresponds to 2.7 billion tons of $\mathrm{CO}_{2}$ emissions each year [3]. The negative side effects of transportation are even worse in cities. Congestion, accidents with pedestrians and cyclists, and limited parking space are significant problems to be addressed. This, coupled with the increasing concentration of people in urban environments (up

Manuscript Accepted: 13 Apr 2017

D. Nicolaides is with the Department of Engineering, University of Cambridge UK (e-mail: dn314@cam.ac.uk)

D. Cebon is with the Department of Engineering, University of Cambridge UK (e-mail: dc@eng.cam.ac.uk)

J. Miles is with the Department of Engineering, University of Cambridge UK (e-mail: jcm91 @eng.cam.ac.uk) to $70 \%$ of the world's population will be in cities by 2050 [4]) have made the shift towards innovative and more sustainable urban transportation imperative.

Novel technologies and policy strategies have been proposed to achieve a more sustainable urban transport sector. On-demand buses [5], shuttle buses, public consultation [6] and travel demand management [7] are some examples. The problem to be addressed in this paper is whether an autonomous taxi service could be adopted as an alternative sustainable mode of transportation.

A critical review is presented to examine whether the proposed technology is capable for alleviating the negative side effects of urban transportation. The study aims to address issues related to environmental impact, social sustainability and required infrastructure. The levels of demand are estimated and then the system performance requirements are defined. A financial analysis is presented to assess the financial viability of such a proposal. The authors do not discuss any legal aspects related with testing and use of autonomous vehicles. This is less of a concern because similar projects have been already built and demonstrated around the world [8], [9], [10], [11].

The city of Cambridge UK has been selected for demonstration. Multiple estate developments have been proposed recently to maintain the University's and City's competitive advantage. Among these the Addenbrooke's site is expected to be completed in the coming years. This large development combines an academic, industrial and urban environment; representing a self-sustaining city. This research is focused on this University's campus.

\section{SustainABILITY ASSESSMENT}

The utilisation of innovative road vehicles is essential to establish a taxi service which meets the sustainable objectives of current and future cities. Such vehicles, also known as Autonomous Pods (Fig. 1), can alleviate the negative side effects of urban transportation. They are 2 seater driverless vehicles, capable of navigating a route in open space without physical guidance [12], [13]. They are an attractive solution within an existing urban context. The impact on environment, social sustainability and required infrastructure are explored in this section. 


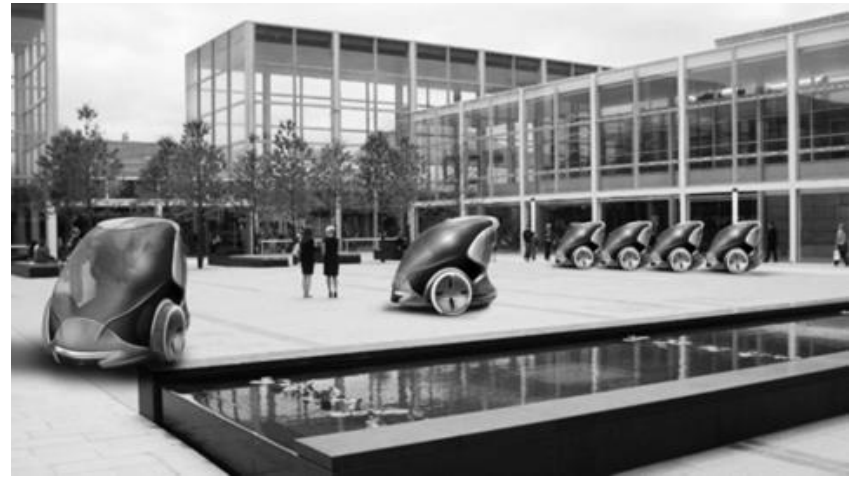

Fig. 1. Autonomous Pods [13]

\section{A. Environmental Impact}

One of the most important characteristics of autonomous pods is that they are electric-propelled vehicles. This allows them to offer significant environmental advantages over conventional vehicles. Firstly, significant reduction of $\mathrm{CO}_{2}$ emissions in comparison with conventional vehicles can be achieved. It was showed in other studies that $90 \%$ reduction of $\mathrm{CO}_{2}$ is feasible by 2050 [14]; provided the current projections for decarbonisation of the electricity grid are achieved. This will substantially decarbonise the transport sector and help alleviate climate change.

Secondly, electricity as an energy source enables energy diversity. This ensures security of energy supply and a broad use of carbon-free energy sources [15]. Electricity can reduce significantly the constant extraction of fossil fuels to supply the transport sector that subject people to conditions that "systematically undermine their capacity to meet their own needs" [16].

Thirdly, autonomous pods could potentially become part of the electricity supply network. Charging the vehicles' batteries or utilising their stored energy could be managed in a smart way [17]. This would be particular advantageous for balancing the electricity supply network and would facilitate the penetration of renewable energy sources. Consequently, autonomous pods will help to reduce $\mathrm{CO}_{2}$ emissions associated with the electricity supply network.

\section{B. Social Sustainability}

The field of intelligent transport and autonomous vehicles has advanced significantly the last decade. Some autonomous taxi services have been built and demonstrated around the world. At early stages, 'Fixed-Path Systems' were mostly common. These systems run on their own dedicated pathways and some examples are the 'ULTra System' at Heathrow Terminal 5 [8] and the '2GetThere' system at Masdar City, UAE [9]. More recently, there has been a lot of interest about 'Roaming Systems'. These vehicles are capable of navigating a route in open space without physical guidance. An example of this system is the Navya vehicle which accommodates 12 passengers and is currently under trial at several different locations around the world including Switzerland, Singapore and UK [10]. Additionally, smaller and more agile 2-4 seater autonomous pods have been recently used for the 'LUTZ Pathfinder' demonstration project at Milton Keynes [11]. Consequently, the technology risk for implementing an autonomous taxi service in the University's campus is limited. It is a proven concept with many lessons to be learnt from various systems around the world.

A comprehensive research methodology to account behavioural factors affecting the acceptance of autonomous pods has not yet been established. However, they have a number of novel features that increase market acceptance and social equity [12].

One of them is autonomy which allows them to be driverless. The current generation of pods are designed to operate at low speeds in restricted and pedestrianised spaces, free of conventional vehicles, where the traffic conditions are much simpler than normal city streets. Furthermore, the human error factor has been removed. This could lead to increased safety for both passenger, pedestrians and cyclists because reliable technology is responsible for the control of the vehicle. Moreover, a driverless vehicle removes any necessary interconnections between the driver and the rolling chassis. This, coupled with relative slow travelling speed have eliminated the need for 'crumple zones' in front of the vehicle. Therefore, the exterior and interior of autonomous pods have been re-designed in a more flexible way for enhanced attractiveness and comfort. Entry and exit to the vehicle can be from the front or rear. This is particularly advantageous for disabled and aged people.

Another fundamental design concept for autonomous pods is connectivity. Connectivity enables communication between a vehicle with other vehicles, networks and the environment. This allows autonomous pods to collect and process large amounts of data for an improved experience of personal mobility in urban environments. Vehicles could determine their optimal route based on real-time information about possible road blockages, congestion, etc. This would make journeys faster, more predictable and more reliable. In the meantime, travel time could be useful for other activities such as working or entertainment whilst experiencing the use of a private vehicle. New service facilities would be also feasible. Call on demand, automating pickup/ drop-off transactions and door-to-door journeys would increase the attractiveness of the system.

Finally, air pollution is less of a concern for the proposed taxi system. Autonomous pods offer zero tailpipe emissions, eliminating the release of noxious pollutants. This, coupled with low operation noise make them an attractive and enjoyable solution for urban areas.

\section{Infrastructure needs}

In autonomous pods the conventional mechanical systems of road vehicles -the drive train, steering and braking systemsare replaced by more compact, flexible and automated electric systems. This reduces significantly the size and mass of the vehicle. They can run without any purpose-built infrastructure and this combined with low travelling speeds up to $12.4 \mathrm{mph}$ $(20 \mathrm{~km} / \mathrm{h})$ allows them to coexist with pedestrians and cyclists within an existing urban context. Even folding autonomous pods are possible for reducing the space needed when they are parked. This could be an attractive feature for cities where 
parking space is limited and expensive.

Autonomous taxi service could be a retrofit solution to an urban transport system by addition of local chagrining infrastructure, but not much else. Non-conductive (wireless) power charging systems for electric vehicles have been under development for some time [18]. The ability to avoid plug-in cables and to use simple low-profile systems that are unaffected by weather conditions is likely to be attractive for urban environments. However, electricity distribution networks may need to be upgraded to deal with the increased future demand but the technology and expertise have been in practice for many years.

\section{LEVELS OF DEMAND}

In this section, the levels of demand for an autonomous taxi service are estimated. Autonomous vehicles are still in the early stages of testing and therefore, a demand forecasting methodology has not been academically established. Nevertheless, the analysis is based on the main principles of transport planning [19] combined with personal judgement and realistic assumptions particular to the city of Cambridge. The first step was Trip Generation for forecasting travel demands. Then, Trip Distribution for matching trips' origins and destinations and finally, Modal Split analysis for determining the degree of satisfaction to use an autonomous pod instead of other mode choices. The Addenbrooke's hospital site was selected to illustrate the analysis but the same methodology could be used as a comprehensive framework to estimate the levels of demand of similar systems in other areas as well.

\section{A. Trip Generation}

The first stage was to estimate the number of trips made in the Addenbrooke's Site. Three type of journeys were considered in this study. Category A includes trips generated from workers, Category B trips generated from visitors for business purposes (including outpatient appointments and hospital visitors) and Category $\mathrm{C}$ includes trips generated from people who visit the site for leisure purposes. Access to reliable information about number of residents, number of workers, students, outpatient appointments, etc. was essential to calculate the number of trips generated. Sources of data were the University of Cambridge Estate Management and Cambridge University Hospitals NHS Foundation Trust [20]. Our assumptions include 15,000 working population by 2020 , 1,000 bed spaces for students and key workers' accommodation and about 3,000 visitors per day, of which 2,900 are visitors for business purposes. The remaining are visitors for leisure purposes. The number of generated trips were also combined with data about the arrival pattern of patients to the Prince of Wales Hospital, which is a large public and teaching hospital in Honk Kong [21], for creating daily profiles. It is noticed that there are significantly more Category A trips than Category B and C trips.

\section{B. Trip Distribution}

The geographic area of interest was divided into zones for distributing the trips between them and identifying the traffic flows. Although the matching of origins with destinations was performed rather qualitatively, the analysis was based on a comprehensive overview of the site regarding concentration of job positions, location of medical and community buildings, transport access to the site, parking places and provision of other public transport services.

\section{Modal Split}

The modal split analysis was performed to calculate the number of people who would use an autonomous pod instead of walking, cycling or taking the bus. The process was based on the concept of utility function which allows the comparison of mode choices based on various modal features [22]. The utility function $u_{k}=a_{1} X_{1}+a_{2} X_{2}+a_{3} X_{3}$ of travel mode $k$ is a function of $X_{i}$, the variables affecting modal choice and $a_{i}$, the weighting factors for each variable. Three main features were chosen to assess the mode choices. These were the Travelling Time, Waiting Time and Price whose weighting factor was chosen as $-0.16,-0.30$ and -0.54 respectively; using the Analytical Hierarchy Process (AHP) technique [23]. The AHP method is a tool to help decision makers to rank alternative options through a comprehensive and rational framework. This method allows us to evaluate the elements of the problem by comparing them to each other two at a time. Rather than concrete data, the decision makers typically use their judgements about the elements' relative strength of preference [24]. This study assumes that (i) Waiting Time is moderately more important than Travelling Time, (ii) Price is strongly more important than Travelling Time and (iii) Price is moderately more important than Waiting Time for choosing a travel mode. The negative signs are due to the negative impact of each variable on the mode's value.

Overall, the levels of demand for a possible autonomous taxi service on the Addenbrooke's Site are shown in Fig. 2 for weekdays and weekends separately. The number of people demanding autonomous pods during the weekends is significantly lower than the weekdays. Mainly because there are less Category A trips for workers traveling to their jobs. It is noticed that up to 200 people would require an autonomous pod during peak hours. This corresponds to 152 pod-trips (trips performed by autonomous pods) per hour; assuming occupancy ratio of autonomous pods at 1.5 (i.e. 1.5 people on average in a pod), 1.0 and 1.5 for Category A, Category B, and Category $\mathrm{C}$ journeys respectively. The levels of demand of an autonomous pod operation on the Addenbrooke's site are summarised in TABLE 1.

TABLE 1

LEVELS OF DEMAND FOR AUTONOMOUS POD OPERATION ON THE ADDENBROOKE'S SITE

\begin{tabular}{lcc}
\hline \hline & Weekday & Weekend \\
\hline Peak people per hour & 200 & 61 \\
People per day & 2,778 & 833 \\
People per year & \multicolumn{2}{c}{808,912} \\
\hline Peak pod-trips per hour & 152 & 69 \\
Pod-trips per day & 2,191 & 1,072 \\
Pod-trips per year & \multicolumn{2}{c}{681,148} \\
\hline \hline
\end{tabular}




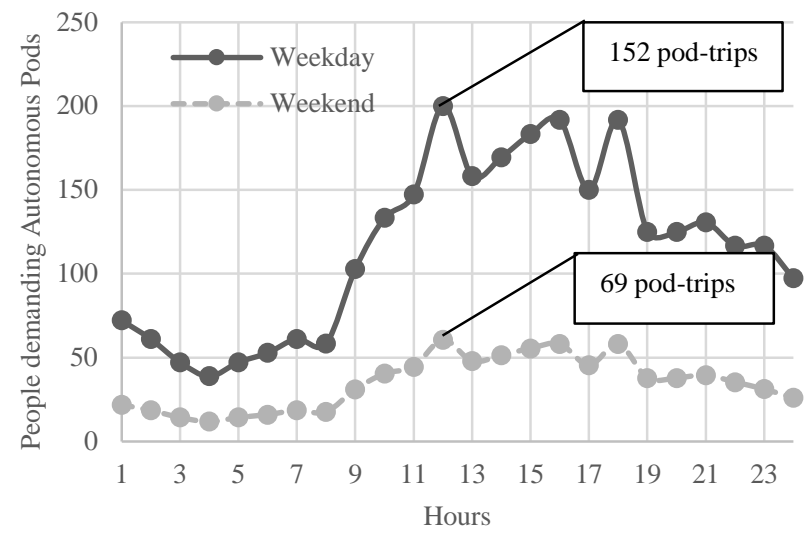

Fig. 2. People demanding autonomous pods through a typical day

\section{System PERFORMANCE REQUiREMENTS}

Based on the levels of demand, the performance requirements can be defined for a practical system. The size of the required fleet, the capacity of the on-board battery and the charging infrastructure are determined in this section. Any potential impacts on the electricity supply grid are also explored.

\section{A. Size of fleet}

The number of autonomous pods required to meet the demand is firstly calculated. It was found that a pod can perform up to 5 trips in an hour; taking into consideration the average time needed for each pod-trip (3.6 minutes), additional time needed for embarking and disembarking the vehicle ( 3 minutes) and any time needed to travel between dropping-off one passenger and collecting the next customer (1 minute). Congestion delays are less of a concern because the use of private cars is prohibited within the area of Addenbrooke's. Nevertheless, a conservative 50\% safety margin was included in the calculations. The number of pods required through the day can be therefore, calculated by dividing the demanded pod-trips by the 5 trips per pod figure. The results are shown in Fig. 3. A fleet of 33 autonomous pods is needed to serve 200 people at peak times (11am-12am) and a total number of 2,778 people per day.

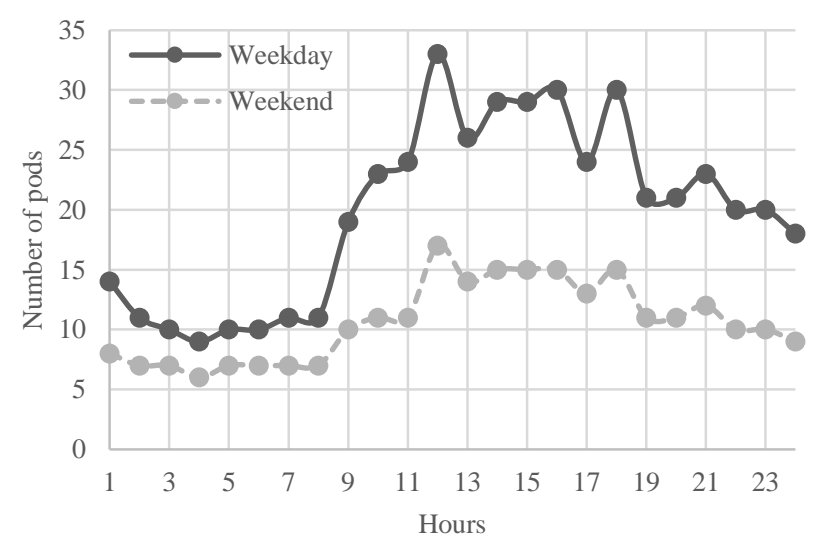

Fig. 3. Number of autonomous pods required through a typical day
Although a central parking and maintenance area is likely to be designated, it is expected that autonomous pods will be distributed within the area of service. This allows vehicles to be closer to customers and therefore, minimise waiting times for customers and energy consumed. The number of autonomous pods required in each zone of the site throughout the day can be calculated by the Trip Distribution and Modal Split processes.

\section{B. Energy requirements - Battery Capacity}

The total number of pod-trips in a weekday was estimated at 2,191 (TABLE 1). Each autonomous pod is therefore responsible for 67 pod-trips per day assuming a fleet of 33 vehicles. The average energy consumption for each pod-trip was found to be $0.18 \mathrm{kWh}$, of which $0.15 \mathrm{kWh}$ is for the actual distance driven for the trip ( 0.75 miles). The remaining energy, $0.03 \mathrm{kWh}$, was added for any distance travelled to pick up a customer ( 0.15 miles). A $0.20 \mathrm{kWh} / \mathrm{mile}$ energy consumption was assumed. Hence, the total energy required for a day was calculated at $12 \mathrm{kWh}$ per pod.

The analysis assumed that an autonomous pod is charged once per day, although smaller and frequent charging boosts could be possible throughout the day. The battery should therefore provide all the energy required for the day. A $15 \mathrm{kWh}$ battery is suggested, taking into consideration a minimum discharged level of $20 \%$ for maximising the life span of the battery.

\section{Power demand}

Data about the power demand of Addenbrooke's were obtained from the Estates and Facilities Management. Average power demand profiles for weekdays and weekends are summarised in Fig. 4. Summer and winter figures are presented separately to explore any alterations due to heating/ air-conditioning load. The base data were logged on the weeks starting 12 July 2016 and 12 December 2016.

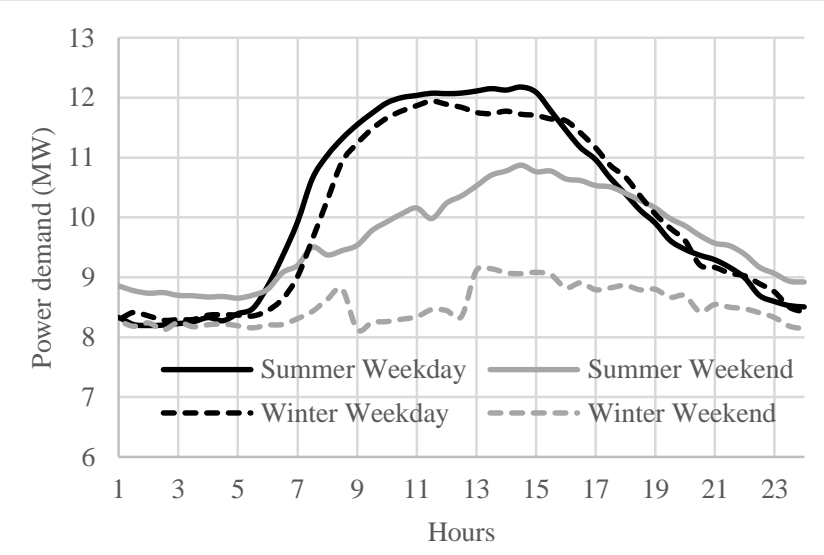

Fig. 4. Daily power demand at Addenbrooke's

\section{Charging Infrastructure}

The charging infrastructure for such a system is calculated in this section. It is noticed in Fig. 4 that there is substantial decrease of power demand during the evening and early morning hours (between 6pm-8am). This offers a substantial 
capacity margin of more than $1 \mathrm{MW}$ for charging the batteries of autonomous pods without augmenting the peak power demand of the site.

A 1C charge rate is advised for Lithium-Ion batteries, usually used in automotive vehicles, for maximising their life span [25]. This means that a minimum 60 minutes charging time is needed for each vehicle using a $15 \mathrm{~kW}$ charger. Hence, a charging infrastructure with 3 chargers is needed to deliver the energy requirements of the proposed taxi service at Addenbrooke's, which includes 33 vehicles.

The installation of more than 3 chargers can be shown to be an inferior approach. The additional power demand of the charging system increases proportionally with the number of installed chargers. The utilisation time of each charger also decreases because a single charger serves fewer vehicles. Most importantly, the cost of the system rises drastically due to the installation of multiple charging stations which involves higher capital costs (purchase of chargers, cables, etc.) and civil engineering expenses (integrating chargers with the infrastructure, connecting charging point to the electricity distribution network, etc.).

\section{E. Implications for the grid}

The additional power demand of the proposed autonomous taxi service at Addenbrooke's was calculated at $45 \mathrm{~kW}$ (3 chargers at $15 \mathrm{~kW}$ apiece). Charging the vehicles during the evening and morning hours (6pm-8am) does not go beyond the minimum available capacity margin of $1 \mathrm{MW}$. The peak power demand of the campus stays unaltered and therefore, no upgrade of the electricity supply is needed to accommodate the new demand.

Furthermore, the additional load corresponds to less than $0.15 \%$ of the current energy consumption at Addenbrooke's. The energy demand of the proposed autonomous taxi service was calculated at $123 \mathrm{MWh}$ per year based on 681,148 podtrips per year (as shown in TABLE 1) and $0.18 \mathrm{kWh}$ energy consumption per trip. By contrast, the energy consumed for powering purposes at Addenbrooke's stands currently at approximately 90,000 MWh per year; based on data obtained from the Estates and Facilities Management.

\section{FINANCIAL ANALYSIS}

In this section, a financial analysis is presented to explore the financial viability of the proposed system. The assumptions used for the cost model are divided into capital and operating costs and summarised in TABLE 2. The former category includes costs for the vehicles, supporting systems and any infrastructure modifications including installation of chargers. Furthermore, there will be significant staff costs associated with fleet operations (customer care, vehicle allocation and despatch, etc.), safety and security staff, technical support, cleaning, maintenance, etc. It was assumed that an employee would be needed for every 2 vehicles. There would also be further recurring costs such as electricity and maintenance. The derived cost figures were based on similar autonomous taxi services that have been already built and demonstrated around the world [8], [9], [10], [11].
TABLE 2

ASSUMPTIONS FOR COST MODEL

\begin{tabular}{|c|c|c|}
\hline Cost Variables & $\bar{f}$ & Details \\
\hline \multicolumn{3}{|l|}{ Capital Costs } \\
\hline Autonomous pods & 8,000 & per pod \\
\hline Supporting systems & 500 & per pod \\
\hline Charging Infrastructure & 1,500 & per pod \\
\hline \multicolumn{3}{|l|}{ Operating Costs } \\
\hline Staff wages & 26,000 & A worker for every 2 pods \\
\hline Per mile driven & 0.02 & $0.2 \mathrm{kWh} / \mathrm{mile} \mathrm{X} £ 0.10 / \mathrm{kWh}$ \\
\hline Maintenance & 1,000 & per pod per year \\
\hline
\end{tabular}

A balance sheet for the first 10 years of operation is presented in Appendix. Looking at the figures, a £1,362,296 turnover is possible on the first year of operation for a $£ 2$ ticket price. The total cost figure for the same period, including capital and operating costs, is lower at $£ 817,833$. Hence, the financial analysis revealed that an autonomous taxi service at Addenbrooke's is financially viable with positive net profit achievable within the first year of operation. In addition, alternative revenue streams were identified such as income from memberships and advertisements. Such revenue streams were not considered in this study but they could be potentially included in a future more detailed financial appraisal.

Fig. 5 shows the number of peak pod-trips per hour for various ticket prices. As was expected, the number of peak pod-trips per hour is reduced when the ticket price increases. The use of autonomous pods is less desirable among the other mode choices according to the modal split process. By contrast, the number of peak pod-trips per hour increases when the ticket price is lower. TABLE 3 shows the results of the sensitivity analysis.

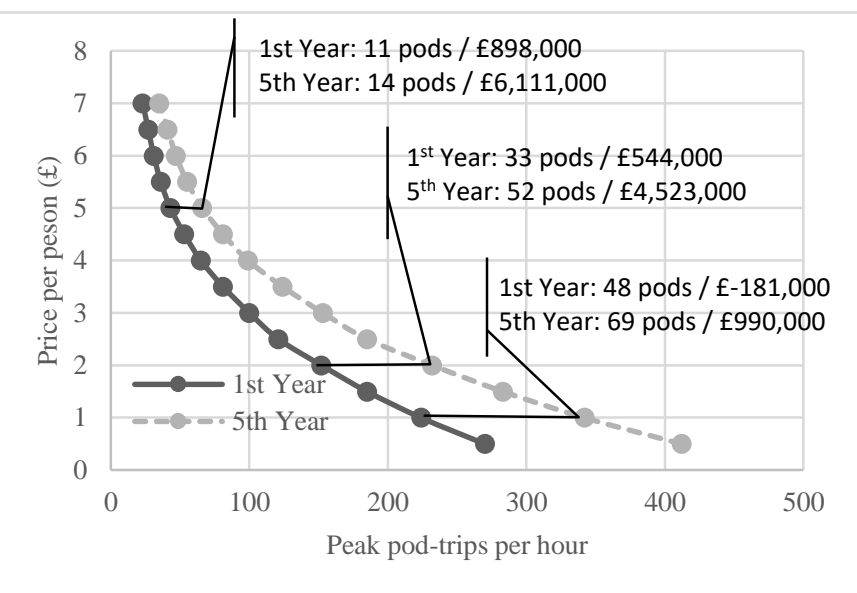

Fig. 5. Addenbrooke's Site - Peak Trips per hour relative to ticket price

TABLE 3

ADDENBROOKE'S SITE - TICKET PRICE SENSITIVITY ANALYSIS

\begin{tabular}{lcccccc}
\hline \hline $\begin{array}{l}\text { Price }(£ \\
\text { per } \\
\text { person })\end{array}$ & $\begin{array}{c}\text { Peak } \\
\text { trips } \\
\text { per } \\
\text { hour }\end{array}$ & $\begin{array}{c}\text { Number } \\
\text { of pods }\end{array}$ & $\begin{array}{c}\text { Net } \\
\text { Profit } \\
(£ k)\end{array}$ & $\begin{array}{c}\text { Peak } \\
\text { trips } \\
\text { per } \\
\text { hour }\end{array}$ & $\begin{array}{c}\text { Number } \\
\text { of pods }\end{array}$ & $\begin{array}{c}\text { Net } \\
\text { Profit } \\
(£ k)\end{array}$ \\
\hline 0.5 & 270 & 56 & -776 & 412 & 83 & $-2,431$ \\
1 & 224 & 48 & -181 & 342 & 69 & 990 \\
1.5 & 185 & 39 & 273 & 283 & 57 & 3,334
\end{tabular}




\begin{tabular}{lcccccc}
2 & 152 & 33 & 544 & 232 & 52 & 4,523 \\
2.5 & 121 & 25 & 780 & 185 & 37 & 5,778 \\
3 & 100 & 22 & 854 & 153 & 31 & 6,134 \\
3.5 & 81 & 19 & 878 & 124 & 25 & 6,319 \\
4 & 65 & 17 & 863 & 99 & 20 & 6,285 \\
4.5 & 53 & 13 & 900 & 81 & 17 & 6,147 \\
5 & 43 & 11 & 898 & 66 & 14 & 6,111 \\
5.5 & 36 & 9 & 902 & 55 & 11 & 5,991 \\
6 & 31 & 8 & 903 & 47 & 10 & 5877 \\
6.5 & 27 & 7 & 899 & 41 & 9 & 5,855 \\
7 & 23 & 6 & 926 & 35 & 8 & 5,898 \\
\hline \hline
\end{tabular}

\section{CONCLUSIONS}

An autonomous taxi scheme was proposed as a sustainable urban transport system for current and future cities. A critical review has shown that such a system could deliver environmental benefits and improve the experience of personal mobility in closed urban environments. A methodology was proposed to estimate the levels of demand of such a system and set the performance requirements. The methodology was presented through a case study of the Addenbrooke's Hospital site in Cambridge but it could be considered as a comprehensive framework for similar systems in other areas as well.

For the Addenbrooke's site, it was shown that a fleet of 33 vehicles would be needed to serve a total number of 2,778 people per day. The capacity of the on-board battery was found to be $15 \mathrm{kWh}$ and a charging infrastructure of 3 chargers at $15 \mathrm{~kW}$ was suggested to deliver the energy requirements of the system. The additional power load was calculated at $123 \mathrm{MWh}$ per year which corresponds to less than $0.15 \%$ of the current energy consumption at Addenbrooke's. The peak power demand of the site would be unaltered, provided charging of the vehicles is performed between the evening and morning hours. A financial analysis showed that such a system is financially viable with positive net profit even from the first year of operation, assuming a ticket price around £1-2 per person.

The paper has shown that technologies for current and future cities already exist to deliver environmental benefits and social equity. This potential should be recognised from governments and city councils for promoting research on technologies that could make a big difference in the future.

\section{REFERENCES}

[1] J. Kenworthy and F. Laube, "An International Sourcebook of Automobile Dependence in Cities," Colorado, 2000.

[2] World Health Organisation, "The World Report on Road Traffic Injury Prevention," 2004

[3] International Energy Agency, "World Energy Outlook 2008," 2008.

[4] UN-Habitat, State of the World's Cities 2008/2009 - Harmonious Cities. UN-Habitat, 2008.

[5] K. Tsubouchi, H. Yamato, and K. Hiekata, "Innovative on-demand bus system in Japan," IET Intell. Transp. Syst., vol. 4, no. 4, pp. 270-279, 2010.

[6] United Nations, "Sustainable Urban Transportation," A Guide for Sustainable Urban Development in the 21st Century, 2010. [Online]. Available: https://sustainabledevelopment.un.org/index.php?page=view\&type $=400$ $\& n r=633 \& m e n u=35$.

[7] State of Green, "Think Denmark," Sustainable urban Transportation, 2016. [Online]. Available: https://stateofgreen.com/files/download/9642.

[8] ARUP, "Heathrow Personal Rapid Transit System," 2015. [Online]. Available:

http://www.arup.com/projects/heathrow_personal_rapid_transit_prt.

[9] C. Helsdingen, "Masdar PRT @99.7\% Since 2010," Masdal new, 2016. [Online]. Available: http://www.2getthere.eu/masdars-prt-systemfunctions-99-since-launch-2010/.

[10] Navya, "Navya Arma," 2014. [Online]. Available: http://navya.tech/?lang=en.

[11] Catapult Transport Systems, "Self-driving pods," 2017. [Online]. Available: https://ts.catapult.org.uk/current-projects/self-driving-pods/.

[12] W. Mitchell, C. Borroni-Bird, and L. Burns, Reinventing the automobile: Personal urban mobility for the 21 st century. Massachusetts Institute of Technology Press, 2010.

[13] A. Wade, "Pods are coming up in the world," The Engineer, pp. 38-40, 2016.

[14] D. Nicolaides, D. Cebon, and J. Miles, "Prospects for electrification of freight transportation," IEEE Syst. J., vol. PP, no. 99, pp. 1-12, 2017.

[15] S. Awerbuch, "Portfolio-Based Electricity Generation Planning: Policy Implications For Renewables And Energy Security," Mitig. Adapt. Straategies Glob. Chang., vol. 11, no. 3, pp. 693-710, 2006.

[16] C. M. Ainger and R. A. Fenner, Sustainable Infrastructure: Principles into Practice. UK: ICE Publishing, 2013.

[17] B. Kramer, S. Chakraborty, and B. Kroposki, "A Review of Plug-in Vehicles and Vehicle-to-Grid Capability," in Industrial Economics, 2008, pp. 2278-2283.

[18] T. M. Fisher, K. B. Farley, Y. Gao, H. Bai, and Z. T. H. Tse, "Electric vehicle wireless charging technology: a state-of-the-art review of magnetic coupling systems," Wirel. Power Transf., pp. 1-10, Sep. 2014.

[19] M. G. McNally, "The Four Step Model," in Handbook of Transport Modeling, 2nd Editio., Emerald Group Publishing Limited, 2007, pp. $35-53$.

[20] Cambridge University Hospitals, "2020 Vision at Addenbrooke's," Cambridge, UK, 2012.

[21] Y.-H. Kuo, O. Rado, B. Lupia, J. M. Y. Leung, and C. A. Graham, "Improving the efficiency of a hospital emergency department: a simulation study with indirectly imputed service-time distributions," Flex. Serv. Manuf. J., vol. 28, no. 1-2, pp. 120-147, Jun. 2016.

[22] T. F. Golob and M. J. Beckmann, "A Utility Model for Travel Forecasting," Transp. Sci., vol. 5, no. 1, pp. 79-90, Feb. 1971.

[23] T. Saaty, "Decision making with the analytic hierarchy process," Int. J. Serv. Sci., vol. 1, no. 1, pp. 83-98, 2008.

[24] T. L. Saaty, "Relative measurement and its generalization in decision making why pairwise comparisons are central in mathematics for the measurement of intangible factors the analytic hierarchy/network process," Rev. la Real Acad. Ciencias Exactas, Fis. y Nat. Ser. A. Mat., vol. 102, no. 2, pp. 251-318, Sep. 2008.

[25] Battery University, "Charging Lithium-ion," 2017. [Online]. Available: http://batteryuniversity.com/learn/article/charging_lithium_ion_batteries

\section{APPENDIX: BALANCE SHEET FOR AUTONOMOUS POD} OPERATION ON THE ADDENBROOKE'S SITE

\begin{tabular}{|c|c|c|c|c|c|c|c|c|c|c|}
\hline 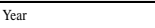 & 1 & 2 & 3 & 4 & 5 & 6 & 7 & 8 & 9 & 10 \\
\hline Growth rate & 0 & 5 & 10 & 15 & 15 & 10 & 5 & 3 & 3 & 2 \\
\hline Number of pods & 33 & 35 & 39 & 45 & 52 & 58 & 61 & 63 & 65 & 67 \\
\hline \multicolumn{11}{|l|}{ Income } \\
\hline Annual Trips & 681,148 & 715,205 & 786,726 & 904,735 & $1,040,445$ & $1,144,490$ & $1,201,714$ & $1,237,765$ & $1,274,898$ & $1,300,396$ \\
\hline our & 152 & 160 & 176 & 202 & 232 & 255 & 268 & 276 & 284 & 290 \\
\hline Annual lnc & $1,362,296$ & $1,430,411$ & $1,573,452$ & $1,809,470$ & $2,080,890$ & $2,288,979$ & $2,403,428$ & 475,531 & $2,549,797$ & $2,600,793$ \\
\hline \multicolumn{11}{|l|}{$\underline{\underline{C o s t s}}$} \\
\hline \\
\hline Pods & 264,000 & 16,000 & 32,000 & 48,000 & 56,000 & 48,000 & 24,000 & 16,000 & 16,000 & 16,000 \\
\hline Supporting systems (f & 16,500 & 1,000 & 2,000 & 3,000 & 3,500 & 3,000 & 1,500 & 1,000 & 1,000 & 1,000 \\
\hline $\begin{array}{l}\text { Charging infrastructure ( } \mathfrak{f}) \\
\text { Operating cost }\end{array}$ & \multicolumn{3}{|c|}{ Operating cost } & 67,500 & 78,000 & 87,000 & 91,500 & 94,500 & 97,500 & 100,500 \\
\hline Electricity costs (t) & 12,833 & 13,475 & 14,822 & 17,046 & 19,602 & 21,563 & 22,641 & 23,320 & 24,020 & 24,500 \\
\hline Maintenance costs (f) & 33,000 & 35,000 & 39,000 & 45,000 & 52,000 & 58,000 & 61,000 & 63,000 & 65,000 & 67,000 \\
\hline Staff Costs $(\mathfrak{f})$ & 442,000 & 468,000 & 520,000 & 598,000 & 676,000 & 754,000 & 806,000 & 832,000 & 858,000 & 884,000 \\
\hline Total $(f)$ & 817,833 & 585,975 & 666,322 & 778,546 & 885,102 & 971,563 & $1,006,641$ & $1,029,820$ & $1,061,520$ & $1,093,000$ \\
\hline \multicolumn{11}{|l|}{ Total } \\
\hline otal per year & 544,463 & 844,436 & 907,130 & $1,030,924$ & $1,195,788$ & $1,317,416$ & $1,396,787$ & $1,445,711$ & $1,488,277$ & $1,507,793$ \\
\hline Vet profit $(f)$ & 544,463 & $1,388,899$ & $2,296,029$ & $3,326,953$ & $4,522,740$ & $5,840,157$ & $7,236,944$ & $8,682,655$ & $10,170,932$ & $11,678,725$ \\
\hline
\end{tabular}

